\title{
Participation of an Energy Hub in Electricity and Heat Distribution Markets: An MPEC Approach
}

Li, Rui; Wu, Qiuwei; Wei, Wei; Mei, Shengwei; Hu, Qinran

Published in:

IEEE Transactions on Smart Grid

Link to article, DOI:

10.1109/TSG.2018.2833279

Publication date:

2019

Document Version

Peer reviewed version

Link back to DTU Orbit

Citation (APA):

Li, R., Wu, Q., Wei, W., Mei, S., \& Hu, Q. (2019). Participation of an Energy Hub in Electricity and Heat Distribution Markets: An MPEC Approach. IEEE Transactions on Smart Grid, 10(4), 3641-3653.

https://doi.org/10.1109/TSG.2018.2833279

\section{General rights}

Copyright and moral rights for the publications made accessible in the public portal are retained by the authors and/or other copyright owners and it is a condition of accessing publications that users recognise and abide by the legal requirements associated with these rights.

- Users may download and print one copy of any publication from the public portal for the purpose of private study or research.

- You may not further distribute the material or use it for any profit-making activity or commercial gain

- You may freely distribute the URL identifying the publication in the public portal 


\title{
Participation of an Energy Hub in Electricity and Heat Distribution Markets: An MPEC Approach
}

\author{
Rui Li, Student Member, IEEE, Wei Wei, Member, IEEE, Shengwei Mei, Fellow, IEEE, \\ Qinran $\mathrm{Hu}$, Member, IEEE, and Qiuwei Wu, Senior Member, IEEE
}

\begin{abstract}
Integration of electricity and heat distribution networks offers extra flexibility to system operation and improves energy efficiency. The energy hub (EH) plays an important role in energy production, conversion and storage in such coupled infrastructures. This paper provides a new outlook and thorough mathematical tool for studying the integrated energy system from a deregulated market perspective. A mathematic program with equilibrium constraints (MPEC) model is proposed to study the strategic behaviors of a profit-driven energy hub in the electricity market and heating market under the background of energy system integration. In the upper level, the EH submits bids of prices and quantities to a distribution power market and a heating market; in the lower level, the two markets are cleared and energy contracts between the EH and two energy markets are determined. Network constraints of physical systems are explicitly represented by an optimal power flow problem and an optimal thermal flow problem. The proposed MPEC formulation is approximated by a mixed-integer linear program via performing integer disjunctions on the complementarity and slackness conditions and binary expansion technique on the bilinear production terms. Case studies demonstrate the effectiveness of the proposed model and method.
\end{abstract}

Index Terms-Energy hub, district heating network, distribution power network, strategic bidding, MPEC

\section{INTRODUCTION}

As modern cities are facing environmental problems nowadays, water and space heating devices which originally burn coals have been gradually replaced by electrical ones such as electric boilers and heat pumps (HPs). Moreover, the district heating system [1], in which thermal energy is produced centrally and distributed through a pipeline network, is becoming popular in countries and regions with long cold winters, owing to its higher efficiency. Electrification of heating devices and mushrooming of district heating networks (DHNs) have created integrated energy distribution systems which harness multiple energy resources in urban areas [2]-[4]. The key component in such a coupled infrastructure is the energy hub (EH) [2], [5], which plays the role of energy production, conversion and

This work was supported by National Natural Science Foundation of China (51621065, U1766203) and Harvard Climate Change Solutions Fund (2018). (Corresponding author: Shengwei Mei)

R. Li, W. Wei, and S. Mei are with the State Key Laboratory of Power Systems, Department of Electrical Engineering, Tsinghua University, Beijing 100084, China (Email: eeairicky@gmail.com, weiwei04@mails.tsinghua.edu.cn, meishengwei@tsinghua.edu.cn).

Q. Hu is with Harvard John A. Paulson School of Engineering and Applied Science 33 Oxford St., Cambridge, MA 02138, USA (Email:qh@ieee.org)

Q. Wu is with Center for Electric Power and Energy (CEE), Department of Electrical Engineering, Technical University of Denmark (DTU) (Email: qw@elektro.dtu.dk). storage. The EH impacts the operation of different physical systems with heterogenous energy carriers, and has the potential to participate in electricity, heat, and natural gas markets at the same time.

In view of the interdependence across different physical infrastructures, extensive efforts have been devoted to the study of modelling, planning, and operation of integrated energy systems with EHs and multi-carrier energy flows since the pioneer work in [2], [5]. A systematic modelling approach was presented in [6] to automatically building the coupling matrix for EHs using the graphic theory. A mixed-integer linear program (MILP) formulation was introduced by [7] which considers more accurate plant performances, such as startup/shutdown operations and variable efficiency curves. For operation related studies, unleashing the flexibility from the coordination of multi-carrier energy flows through EHs is the core target. Except for the basic models in [2], [5], [6], joint optimization of natural gas, heating, and electric power flows was investigated in [8]. A decomposition framework was proposed in [9] for optimization of system energy flows with multiple EHs. The optimal operation strategies of residential and industrial EHs were considered in [10], [11]. To explicitly quantify the impact of uncertainties and risks, the robust optimization approach was applied to EH operation in [12]. A two-point estimate method was employed in [13] to model the uncertainty of solar panel output. A resilient operation model of multi-carrier microgrids was developed in [14] based on mixed integer bi-level program. For planning oriented work, optimal expansion planning of EH was discussed in [15] which considers energy efficiency, emission, and reliability. Reliability-aware optimal planning models were presented in [16], [17] to design the multi-carrier energy systems and EHs. The optimal planning of EH considering operation uncertainty constraints was investigated in [18]. In [19], [20], distributed renewable energy and emission reduction were taken into account in the planning of EHs, respectively.

In aforementioned research, an implicit assumption is that a central authority is in charge of the whole system. However, in current practice, the power distribution network (PDN) and DHN are managed by different sectors. The EH could also be owned by a third-party entity and unwilling to accept mandatory orders. With the development of smart grid technologies, the distribution power market shows its advantages in dispatching available assets in the optimal way, and has attracted major attentions in recent years [21]-[23]. Although the heating market is not as competitive and mature as the 
electricity market, it is attracting increasing attention from researchers, due to development of district heating systems [1]. Heating market organization is discussed in [24], which can be categorized into regulated markets (such as China, Russia) and deregulated markets (such as Denmark, Sweden). Heat pricing scheme is a key issue and receives a lot of research efforts. For regulated markets, a cost-plus method is presented in [25], where the heat price is released and fixed by a government agency. For deregulated markets, in a similar vein to the power market, the marginal pricing scheme could reflect the real-time value of resources, and has been studied in existing literature, for example, the shadow price method [26], the locational marginal price [27], [28], and the equivalent marginal cost [29]. A comprehensive survey can be found in [30]. Energy markets at the distribution level will provide unique opportunities for energy system integration and promoting energy transactions. In a deregulated market, no one has full control authority on all the resources in the network.

Strategic behavior in multi-resource energy markets has been studied. A prototype integrated heat-power system was built in Denmark [31] to study the interaction between heat market and power market. A multi-layer trading framework was investigated in [32], and was formulated as a bilevel program. A bilevel programming model is proposed in [33] for the optimal energy management of $\mathrm{EH}$, which acts as an intermediary agent between the power and natural gas distribution systems. The competition among EHs in demand side management was represented by a Nash game in [34], [35]. Moreover, the optimal bidding strategy of an $\mathrm{EH}$ in the electricity market is investigated in [36] to consider the uncertain market prices with a stochastic approach. Nevertheless, network models are neglected in above work, because they focus on the residential-level energy hub. A single hub has little impact on the distribution network. The distribution-level EH considered in this paper provides energy to PDN and DHN, and could influence their production schedules.

This paper proposes an MPEC model to study the strategic behaviors of a profit-driven $\mathrm{EH}$ in the distribution-level electricity market and heating market under the background of energy system integration. The electricity and heating markets are cleared according to an optimal power flow (OPF) problem and an optimal thermal flow (OTF) problem, respectively, which determine energy contracts with the EH. The EH submits prices and quantities to the markets by anticipating the consequence of clearing results. The MPEC formulation is then approximated by an MILP. Integer disjunction is performed on KKT optimality conditions associated with two market clearing problems, and the binary expansion technique is used to linearize the bilinear production terms. The contribution of this paper is that it provides thorough mathematical model and computational method for studying the integrated energy system from a deregulated market point of view.

The rest of this paper is organized as follows. The electricity and heating market clearing problems are presented in Section II. The strategic bidding problem of the EH is formulated as an MPEC and transformed into an MILP in Section III. Case studies are conducted in Section IV, followed by conclusions in Section V.

\section{Market Clearing Models}

\section{A. Market Settings and Assumptions}

We focus on the strategic bidding of the EH by leveraging the flexibility offered by electricity storage unit (ESU) and thermal storage unit (TSU) as well as cross-arbitrage potentials among electricity, heat, and gas markets. Following assumptions are made.

1) We center on the day-ahead electricity and heating markets and use load forecast data. Uncertainty is neglected for model conciseness but can be incorporated using the scenario approach, in case of need. Real-time discrepancy between generation and demand can be balanced in a real-time market, which is not considered in this preliminary research. The two markets are independently operated by an electricity market operator (EMO) and a heat market operator (HMO). More discussions on coping with uncertainties can be found at the end of Section III.

2) The energy hub gets payment following a pay-as-bid agreement. The PDN and the DHN are connected through an EH. Power flow status in the PDN is formulated by the linearized branch flow model [37], which is suitable for distribution network studies. Thermal status in the DHN is described by the combined hydraulic and thermal formulation with constant mass flow rates, which results in a linear thermal flow model. The EH submits its electricity (heat) offering/bidding prices and quantities to the EMO (HMO), who subsequently clears the electricity (heating) market to minimize total production cost. The EH then receives the energy contracts and get payment according to the price bids. The bidding strategies in the two markets are highly correlated owing to the energy conversion capability.

3) The prices of electricity and heat are restricted by certain agreements. In fact, bidding a high price is not always the optimal strategy because it leads to a lower market share (EMO and HMO will resort to local generation assets instead of purchasing energy from the hub). From the power market side, the energy hub is a prosumer: it can either consume and offer electricity; From the heating market side, it is a producer, and we don't consider heat import for two reasons: first, heating market is still under study and less mature than the power market, and the heating system infrastructure is less sophisticated than the smart grid, whether bidirectional thermal energy deliver, measurement, and trading are easily supported is unclear; second, the gap between peak and valley prices of heat may not be as large as that of electricity, so arbitrage opportunity in the heating market is not very significant. Nonetheless, the proposed method has no difficulty in modeling a heat prosumer from the mathematical perspective.

In the following, we envision a deregulated heat market which is cleared once an hour based on an OTF problem. Similar to the deregulated power market, the OTF based market clearing can dispatch available resources in the optimal way from an economic perspective, so we believe such a paradigm is promising to be deployed in the future heating markets. 


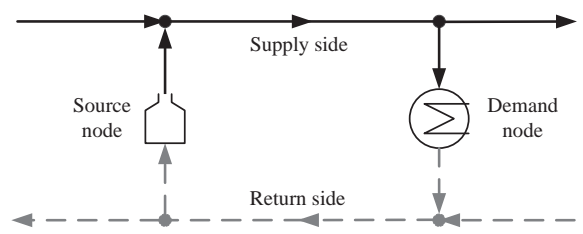

Fig. 1. Illustration of a DHN.

\section{B. OTF and Heating Market Clearing}

A DHN usually consists of a supply pipeline network and a return pipeline network with identical topology, which is illustrated in Fig. 1. Water is heated by heat sources, and injected into supply pipes; at a certain node, hot water flows from the supply side to the return side, and thermal energy is withdrawn by a heat exchanger and delivered to the consumer; At the return side, the water with relative low temperature is send back to heat sources.

The mathematical model of a DHN is comprehensively developed in [38], which consists of a hydraulic part and a thermal part. The hydraulic condition in a DHN should be adjusted to guarantee a feasible solution of the thermal part. Conceptually, the thermal part include three kinds of constraints

1) Heat demand/supply

$$
h=c_{p} \dot{m}\left(\tau^{S}-\tau^{R}\right)
$$

where $c_{p}$ is the specific heat capacity of water; $\dot{m}$ is the water mass flow rate in the pipeline connecting the supply and return networks; $\tau^{S}$ and $\tau^{R}$ are temperatures at the supply side and return side, respectively; $\tau^{S}>\tau^{R}$ always holds. At heat load (source) nodes, water traverses from the supply (return) side to the return (supply) side. In the OTF model, (1) is applied to every pipe across the supply and return networks.

The heating system has large thermal inertial. For building space heating, the customer sets a reference temperature profile, which is translated into a heat demand curve by the smart home appliance. Hence the thermal inertial effect will be considered during the construction of heat demand curve, which can be separated from the market clearing problem.

2) Pipeline model

When water traverses in the supply and return pipelines, its temperature drops due to the inevitable heat loss. For any pipe in either the the supply network or the return network, the following relation holds

$$
\tau^{\text {out }}=\left(\tau^{i n}-\tau^{a m}\right) \mathrm{e}^{-\lambda_{b} l_{b} / c_{p} \dot{m}}+\tau^{a m}
$$

where $\tau^{\text {in }}$ and $\tau^{\text {out }}$ are the inlet and outlet temperatures of the pipe; $\tau^{a m}$ is the ambient temperature; $\lambda_{b}$ is the heat transfer coefficient of the pipe per unit length, and $l_{b}$ is the length of the pipe. $\dot{m}$ is the mass flow rate from the inlet to outlet. In the OTF model, (2) is applied to every pipe in the supply and the return networks.

The ambient temperature $\tau^{a m}$ in (2) is treated as a constant, because most heating systems consist of an underground pipeline network, the change of ambient temperature is relative small, and thus neglected. For the on-ground pipeline network, we can incorporate time-varying ambient temperature $\tau_{t}^{a m}$, and the time interval is one hour. Such data can be retrieved from weather forecast.

The time frame of thermal transients in pipelines depends on the spatial scale of the DHN and the mass flow velocity. If the network is small, the system can reach a thermal equilibrium in a few minutes, whereas the market is cleared once a hour, so temperature transients in pipelines can be neglected in such circumstance. If the DHN scatters in a large area, the transient effect in pipelines could be prominent. Since modeling transients in water pipelines involves a non-linear model [4], the heating market clearing problem will become challenging to solve. More tractable formulation or approximation model remains an open problem. A simple remedy is to regulate the mass flow velocity to shorten the transient process [39].

3)Fluid mix at confluence node

When water flows with different temperatures come across at a confluence node, the temperature of the mixed fluid is determined by the energy conservation law, which gives

$$
\tau^{m i x}=\frac{\sum_{b \in L_{E}(i)}\left(\tau_{b}^{\text {out }} \dot{m}_{b}\right)}{\sum_{b \in L_{E}(i)} \dot{m}_{b}}
$$

where $L_{E}(i)$ is the set of pipes whose outlet connects to node $i ; \tau_{b}^{\text {out }}$ is the water temperature at the outlet of pipe $b \in L_{E}(i)$; $\dot{m}_{b}$ is the mass flow rate in pipe $b \in L_{E}(i)$. The mixed fluid leaves the confluence node with the same temperature,

$$
\tau_{b}^{i n}=\tau^{m i x}, \forall b \in L_{B}(i)
$$

where $L_{B}(i)$ is the set of pipes whose inlet connects to node $i$. In the OTF model, (3)-(4) should be applied to the supply side of every source node and the return side of every load node.

At the return side of every source node and the supply side, water flow diverges and the temperature remains the same,

$$
\tau_{b}^{\text {out }}=\tau_{b^{\prime}}^{i n}, \forall b \in L_{E}(i), \forall b^{\prime} \in L_{B}(i)
$$

The thermal operating status of a DHN can be described by the inlet and outlet temperatures of pipelines in the supply and return networks, as well as the supply side and return side temperatures of pipelines crossing the two networks. All temperature variables are encapsulated in vector $\tau$. Vector $\mathbf{h}$ denotes the output of heat sources. The thermal flow of a DHN can be written in a compact form as,

$$
\begin{aligned}
A_{H} \mathbf{h}+B_{H}(\dot{\mathbf{m}}) \tau & =b_{H} \\
C_{H} \mathbf{h}+D_{H}(\dot{\mathbf{m}}) \tau & \leq d_{H}
\end{aligned}
$$

where $A_{H}, b_{H}, C_{H}$ and $d_{H}$ are constant coefficient matrixes; $B_{H}(\dot{\mathbf{m}})$ and $D_{H}(\dot{\mathbf{m}})$ are coefficient matrixes depending on the mass flow rates $\dot{\mathbf{m}}$. Thermal flow (1) through (5) are considered in (6a). Lower and upper bounds of $\tau$ and $\mathbf{h}$ have been taken into account in (6b). Clearly, (6) is nonlinear and con-convex. In practical, the DHN is usually operated in simpler ways, in which either the mass flow rates or the nodal temperatures are fixed. In this work, we adopt the former one, i.e., mass flow rates $\dot{\mathbf{m}}$ are fixed and constraint set (6) becomes linear with nodal temperatures and heating source output being decision variables.

In the envisioned heating market, the operator seeks the most 


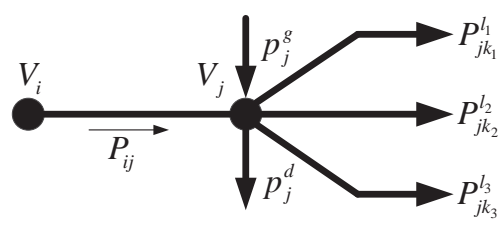

Fig. 2. Typical Topology of a PDN.

economic dispatch of heat sources. From the energy balance perspective, the operation cost largely depends on the total output of heat sources, which is equal to the heat load plus pipeline losses. In what follows, we will show that mass flow rates $\dot{\mathbf{m}}$ have little impact on pipeline losses.

Heat loss in a pipeline can be calculated as,

$$
\Delta E=c_{p} \dot{m}\left(\tau^{\text {in }}-\tau^{\text {out }}\right)
$$

Substituting (2) into (7) results in,

$$
\Delta E=c_{p} \dot{m}\left[\left(\tau^{i n}-\tau^{a m}\right)\left(1-\mathrm{e}^{-\frac{\lambda_{b} l_{b}}{c_{p} m}}\right)\right]
$$

where $0<\lambda_{b} l_{b} / c_{p} \dot{m} \ll 1$. Consider the relation $\mathrm{e}^{-x} \approx 1-x$, we obtain,

$$
\Delta E \approx c_{p} \dot{m}\left(\tau^{i n}-\tau^{a m}\right) \frac{\lambda_{b} l_{b}}{c_{p} \dot{m}}=\lambda_{b} l_{b}\left(\tau^{i n}-\tau^{a m}\right)
$$

From the above equation, we can see that the pipeline loss $\Delta E$ does not depend on the mass flow rate $\dot{m}$. This means that as long as (6) is feasible, the hydraulic condition has little impact on the cost. Therefore, $\dot{\mathbf{m}}$ can be set in prior, corresponding to the constant flow and variable supply temperature operating mode in [40].

We assume traditional heat sources in the DHN are coalfired and gas-fired boilers, whose production costs are convex quadratic functions of their output. The EH bids an offering price $\zeta^{b}$ and a maximum quantity $h_{m}^{b}$ it is willing to provide. They are treated as constants in the heating market. Finally, the heating market clearing problem is given by,

$$
\begin{aligned}
\min _{\mathbf{h}, \tau} & \frac{1}{2} \mathbf{h}^{T} Q_{H} \mathbf{h}+\mathbf{c}_{h}^{T}\left(\zeta^{b}\right) \mathbf{h} \\
\text { s.t. } & A_{H} \mathbf{h}+B_{H}(\dot{\mathbf{m}}) \tau=b_{H} \\
& C_{H} \mathbf{h}+D_{H}(\dot{\mathbf{m}}) \tau \leq d_{H}\left(h_{m}^{b}\right)
\end{aligned}
$$

where objective (8a) is to minimize the total cost, including production costs of traditional boilers and payment to the $\mathrm{EH}$; (8b) and (8c) are the thermal flow status of the DHN. Since (8) is a convex quadratic program, it can be readily solved.

\section{C. $O P F$ and Power Market Clearing}

The PDN has a radial topology. The typical connection is shown in Fig 2. Power flow in a PDN can be described by the linearized branch flow model [37], [41]

$$
\begin{gathered}
P_{i j}+p_{j}^{g}=\sum_{k \in \pi(j)} P_{j k}+p_{j}^{d} \\
Q_{i j}+q_{j}^{g}=\sum_{k \in \pi(j)} Q_{j k}+q_{j}^{d} \\
U_{j}=U_{i}-\frac{r_{i j} P_{i j}+x_{i j} Q_{i j}}{U_{0}}
\end{gathered}
$$

where $P_{i j}$ and $Q_{i j}$ are active power and reactive power in distribution lines; $p_{j}^{g} / p_{j}^{d}$ and $q_{j}^{g} / q_{j}^{d}$ are active and reactive power generation/demand at bus $j ; U_{j} / U_{0}$ is voltage magnitude at bus $j /$ slack bus; $r_{i j}$ and $x_{i j}$ are line resistance and reactance.

In the distribution system study, the linearized branch flow model is more appropriate than the widely used DC power flow model for transmission networks which neglects reactive power and assumes constant bus voltage magnitudes. These factors are important considerations in distribution system operation, and taken into account in (9)-(11). The linearized branch flow model is broadly employed in voltage control and renewable generation dispatch related work, such as [42], [43]. Because the model is lossless, it may not be accurate enough for calculating LMPs [44]. Nevertheless, the energy hub receives a pay-as-bid revenue, and LMP is not needed.

The EH bids an offering price $\xi^{b}$ and purchases electricity from the power market at a price $\chi^{b}$. Then the PDN operator clears the market by minimizing the total cost,

$$
C_{P D N}=\sum_{j}\left[a_{j}\left(p_{j}^{g}\right)^{2}+b_{j} p_{j}^{g}\right]+\xi^{b} p^{g b}-\chi^{b} p^{d b}
$$

where the first term represents generation cost; $\left(a_{j}, b_{j}\right)$ are coefficients of the quadratic function. Define $p_{0}^{g}=\sum_{j \in \pi(0)} P_{0 j}$ the total power delivered from the transmission network, furthermore, $a_{0}=0, b_{0}$ is the electricity price at the transmission network. The second (third) term is paid to (by) the EH for purchasing (consuming) energy at a rate of $p^{g b}\left(p^{d b}\right)$.

Denote by $\mathbf{p}$ the generation dispatch $p_{j}^{g}$ and energy transactions $p^{g b}, p^{d b}$ with the EH, $p_{m}^{g b}$ and $p_{m}^{d b}$ are respectively the maximal electricity quantities the $\mathrm{EH}$ is willing to provide or purchase, $\mathbf{x}$ the remaining variables. The power market clearing problem is given in a compact form,

$$
\begin{aligned}
\min _{\mathbf{p}, \mathbf{x}} & \frac{1}{2} \mathbf{p}^{T} Q_{P} \mathbf{p}+\mathbf{c}_{p}^{T}\left(\xi^{b}, \chi^{b}\right) \mathbf{p} \\
\text { s.t. } & A_{P} \mathbf{p}+B_{P} \mathbf{x}=\mathbf{b}_{P} \\
& C_{P} \mathbf{p}+D_{P} \mathbf{x} \leq \mathbf{d}_{P}\left(p_{m}^{g b}, p_{m}^{d b}\right)
\end{aligned}
$$

where (13b) collects equality constraints (9)-(11); (13c) stands for lower and upper bounds for decision variables.

\section{Strategic Bidding of the Energy Hub}

\section{A. EH model}

Conceptually, an energy hub is a black box component with multiple energy inputs and outputs. It can be implemented by integrating some mainstream energy conversion and storage facilities together, say, combined heat and power (CHP) plants, electrical-powered or gas-fired boilers, air-source and groundsource heat pumps, as well as electricity and heat storage units 


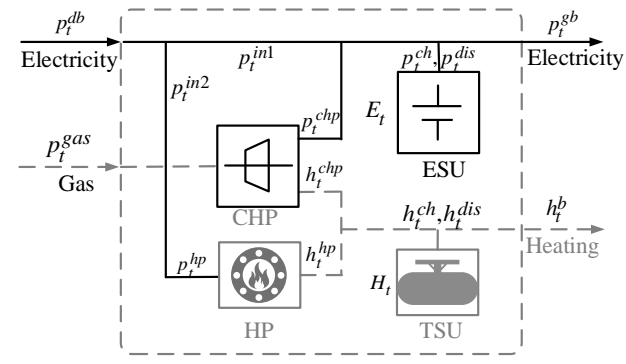

Fig. 3. Schematic of the EH.

[31]. Future energy hubs may be built based on compressedair energy storage systems [45], [46] and concentrating solar power plants [47], [48]. We consider an EH sketched in Fig. 3 , which links a PDN and a DHN. The electricity input is supplied by the PDN, and the natural gas input is supplied by a gas company. Different from a residential one, the EH considered here can sell electricity and heat to the PDN and DHN, respectively, at its output side. In the EH, electricity can be used to charge an electricity storage unit (ESU), or consumed by a HP which produces heat. Natural gas is burnt by a CHP unit to produce electricity and heat. Heat can be stored in a thermal storage unit (TSU) if necessary. The operating constraints include the following:

$$
\begin{gathered}
p_{t}^{i n 1}+p_{t}^{g a s} \eta_{e}^{c h p}+p_{t}^{d i s}-p_{t}^{c h}=p_{t}^{g b}, \forall t \\
p_{t}^{i n 2} \eta^{h p}+p_{t}^{g a s} \eta_{h}^{c h p}+h_{t}^{d i s}-h_{t}^{c h}=h_{t}^{b}, \forall t \\
p_{t}^{d b}=p_{t}^{i n 1}+p_{t}^{i n 2}, \forall t \\
E_{t+1}=E_{t}+p_{t}^{c h} \eta_{+}^{e s u}-p_{t}^{d i s} / \eta_{-}^{e s u}, \forall t \\
H_{t+1}=H_{t}+h_{t}^{c h} \eta_{+}^{t s u}-h_{t}^{d i s} / \eta_{-}^{t s u}, \forall t \\
p_{\min }^{g b} \leq p_{t, m}^{g b} \leq p_{\max }^{g b}, \forall t \\
p_{\min }^{d b} \leq p_{t, m}^{d b} \leq p_{\max }^{d b}, \forall t \\
h_{\min }^{b} \leq h_{t, m}^{b} \leq h_{\max }^{b}, \forall t
\end{gathered}
$$

Upper and lower bounds of other variables

where $p_{t}^{g a s}$ is the inflow of consumed gas fuel, $p_{t}^{g b}$ and $h_{t}^{b}$ are the cleared amount of electric power and thermal energies in the respective markets, and $p_{t}^{d b}$ is the delivered power from the electricity market. These variables are not directly controlled by the $\mathrm{EH}$, instead, they are determined from the market clearing problems. $E_{t}$ and $H_{t}$ are the stored electricity and heat in the ESU and TSU, respectively. $p_{t}^{c h}$ and $p_{t}^{d i s}$ are the charging and discharging power of the ESU, respectively. $h_{t}^{c h}$ and $h_{t}^{\text {dis }}$ are the charging and discharging power of the TSU. Physical meaning of other variables are depicted in Fig.3. $p_{t, m}^{g b}$ and $p_{t, m}^{d b}$ are the electricity quantity offer and bid, respectively. $h_{t, m}^{b}$ is the heat quantity offer. (14a) and (14b) define the electric and thermal balance inside the hub; (14c) determines the required electric power demand; the state-of-charges (SoCs) of ESU and TSU are described in (14d) and (14e), respectively. We assume that the final $\mathrm{SoC}$ is identical to the initial one, i.e., $E_{T}=E_{0}, H_{T}=H_{0}$; the bounds of $p_{t, m}^{g b}, p_{t, m}^{d b}$, and $h_{t, m}^{b}$ are

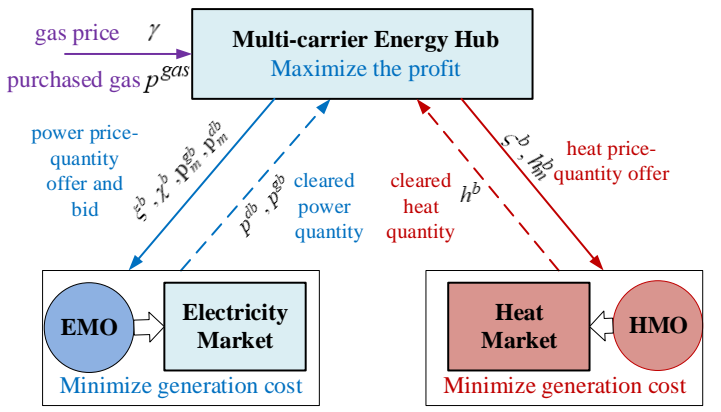

Fig. 4. Framework of the integrated electricity and heat market.

limited in (14f), (14g), and (14h), respectively; the bounds of other variables are collected in (14i). Simultaneous charging and discharging are prevented by introducing binary variables in the charging/discharging rate constraints in (14i).

\section{B. MPEC formulation of the Optimal Bidding Model}

The connection of the EH with the PDN and DHN is shown in Fig. 4. It submits quantities and prices of thermal and electric energies in the respective market, and gets paid in accordance with the offering prices. Different energy prices in peak and valley hours precipitate arbitrage opportunities. The EH seeks maximum profit through the following optimization problem:

$$
\begin{aligned}
\max & \left(\zeta^{\mathbf{b}}\right)^{\mathbf{T}} \mathbf{h}^{\mathbf{b}}+\left(\xi^{\mathbf{b}}\right)^{\mathbf{T}} \mathbf{p}^{\mathbf{g b}}-\left(\chi^{\mathbf{b}}\right)^{\mathbf{T}} \mathbf{p}^{\mathbf{d b}}-(\gamma)^{\mathbf{T}} \mathbf{p}^{\text {gas }} \\
\text { s.t. } & \text { EH operating constraints }(14) \\
& \text { heating market clearing (8) } \\
& \text { power market clearing (13) }
\end{aligned}
$$

where price vectors $\zeta^{\mathbf{b}}, \xi^{\mathbf{b}}, \chi^{b}, \gamma$ represent heat offering prices, electricity offering prices, electricity purchasing prices, and gas prices in the day-ahead market, respectively; energy contract vectors $\mathbf{h}^{\mathbf{b}}, \mathbf{p}^{\mathrm{gb}}, \mathbf{p}^{\mathrm{db}}, \mathbf{p}^{\mathrm{gas}}$ stand for the cleared heat quantities, electricity generations, electricity demands, and gas demands, respectively. (15b) encapsulates the EH operating constraints. As energy contracts are determined from the heating market clearing problem in (15c) and power market clearing problem in (15d), the EH bidding model (15) is an MPEC. From the game theoretical point of view, MPEC (15) can be regarded as a single-leader multi-follower Stackelberg game, in which the EH and two markets make sequential decisions. The optimal strategy of $\mathrm{EH}$ and corresponding market clearing results interpret a market equilibrium under Stackelberg competition.

To solve this bilevel model, notice the fact that both of the market clearing problems (8) and (13) render convex quadratic programs. Hence, they can be replaced by their respective KKT optimality conditions, then problem (15) is transformed into a single-level optimization problem. To this end, the KKT optimality conditions are presented as follows,

\section{Heating market clearing}

$$
A_{H} \mathbf{h}+B_{H}(\dot{\mathbf{m}}) \tau=b_{H}
$$




$$
\begin{gathered}
C_{H} \mathbf{h}+D_{H}(\dot{\mathbf{m}}) \tau \leq d_{H}\left(h_{m}^{b}\right) \\
Q_{H} \mathbf{h}+\mathbf{c}_{h}\left(\zeta^{b}\right)+A_{H}^{T} \lambda_{h}+C_{H}^{T} \mu_{h}=\mathbf{0} \\
B_{H}(\dot{\mathbf{m}}) \lambda_{h}+D_{H}^{T}(\dot{\mathbf{m}}) \mu_{h}=0, \mu_{h} \geq \mathbf{0} \\
\mu_{h}^{T}\left(C_{H} \mathbf{h}+D_{H}(\dot{\mathbf{m}}) \tau-d_{H}\left(h_{m}^{b}\right)\right)=0
\end{gathered}
$$

where $\lambda_{h}$ and $\mu_{h}$ are the vectors of dual variables associated with the equality and inequality constraints of the heating market clearing problem (8). Vectors $d_{H}$ and $\mathbf{c}_{h}$ are linear in $h_{m}^{b}$ and $\zeta^{b}$ submitted by the $\mathrm{EH}$, which are treated as constants in the heat market clearing problem. (16a) and (16b) are feasibility constraints of primal variables; (16c) and (16d) are feasibility constraints of dual variables; (16e) represent the complementary slackness conditions.

\section{Power market clearing}

$$
\begin{gathered}
A_{P} \mathbf{p}+B_{P} \mathbf{x}=\mathbf{b}_{P} \\
C_{P} \mathbf{p}+D_{P} \mathbf{x} \leq \mathbf{d}_{P}\left(p_{m}^{g b}, p_{m}^{d b}\right) \\
Q_{P} \mathbf{p}+\mathbf{c}_{p}\left(\xi^{b}, \chi^{b}\right)+A_{P}^{T} \lambda_{p}+C_{P}^{T} \mu_{p}=\mathbf{0} \\
B_{P}^{T} \lambda_{p}+D_{P}^{T} \mu_{p}=\mathbf{0}, \mu_{p} \geq \mathbf{0} \\
\mu_{p}^{T}\left(C_{P} \mathbf{p}+D_{P} \mathbf{x}-\mathbf{d}_{P}\left(p_{m}^{g b}, p_{m}^{d b}\right)\right)=0
\end{gathered}
$$

where $\lambda_{p}$ and $\mu_{p}$ are the vectors of dual variables associated with the equality and inequality constraints of the power market clearing problem (13). Vectors $\mathbf{c}_{p}$ and $\mathbf{d}_{p}$ are linear in $\xi^{b}$, $\chi^{b}, p_{m}^{g b}$, and $p_{m}^{d b}$ submitted by the $\mathrm{EH}$, which are treated as constants in the electricity market clearing problem. (17a) and (17b) are feasibility constraints of primal variables; (17c) and (17d) are feasibility constraints of dual variables; (17e) represent the complementary slackness conditions.

Because the EMO and HMO could dispatch local generators (heat sources) in the PDN (DHN), bidding a high price is not always a good choice for the EH because it may lead to the loss of market share. When congestion and other security constraints are considered, the energy hub might possess strong market power in certain cases. We assume that the $\mathrm{EH}$ and two markets would reach certain agreements on the lower and upper bounds of offering prices to guarantee market fairness. If there are multiple EHs, we can set up an EPEC model [49] to describe competitions among these EHs, while MPEC (15) serves as the essential unit of the EPEC, in which strategies of rivals are regarded constants. The fixed point of bidding strategies from all energy hubs constitutes the equilibrium in the market. Therefore, model (15) provides a reference formulation for studying more complicated problems.

\section{An MILP approximation}

The KKT conditions described in (16) and (17) are still nonlinear and non-convex. The difficulty arises from the complementarity and slackness constraints which have the form of $\mathbf{0} \leq \mathbf{x} \perp \mathbf{y} \geq \mathbf{0}$, as well as production terms $\left(\zeta^{\mathbf{b}}\right)^{T} \mathbf{h}^{\mathbf{b}}$, $\left(\xi^{\mathbf{b}}\right)^{T} \mathbf{p}^{\mathbf{g b}}$, and $\left(\chi^{\mathbf{b}}\right)^{T} \mathbf{p}^{\mathbf{d b}}$ in the objective function (15a).
For the complementarity condition $\mathbf{0} \leq \mathbf{x} \perp \mathbf{y} \geq \mathbf{0}$, we adopt the linearization method in [50] to express it as,

$$
\mathbf{0} \leq \mathbf{x} \leq M \mathbf{z}, \mathbf{0} \leq \mathbf{y} \leq M(\mathbf{1}-\mathbf{z})
$$

where $M$ is a large enough constant; $\mathbf{z}$ is a vector of binary variables with same dimension as $\mathbf{x}$ and $\mathbf{y} ; \mathbf{1}$ is the all-one vector with the same dimension as $\mathbf{z}$. As long as the big-M parameter is large enough, this transformation is exact and no accuracy is lost.

For the bilinear production terms in the form of $x y$ where $x$ and $y$ are two continuous variables, we employ the binary expansion method in [51], [52] to linearize them. Particularly, we use $2^{K}$ discrete points to approximate possible values of $y$ in its feasible interval $\left[y^{l}, y^{m}\right]$, which gives rise to,

$$
y=y^{l}+\Delta y \sum_{k=1}^{K} 2^{k-1} z_{k}
$$

where $z_{k}, k=1, \cdots, K$ are binary variables, and the step size $\Delta y$ is given by,

$$
\Delta y=\frac{y^{m}-y^{l}}{2^{K}}
$$

As such, $x y=x y^{l}+\Delta y \sum_{k=1}^{K} 2^{k-1} x z_{k}$. Let $v_{k}=x z_{k}, k=$ $1, \cdots, K$, the bilinear term $x y$ can be formulated by,

$$
\begin{gathered}
x y=x y^{l}+\Delta y \sum_{k=1}^{K} 2^{k-1} v_{k} \\
0 \leq x-v_{k} \leq x^{m}\left(1-z_{k}\right), \forall k \\
0 \leq v_{k} \leq x^{m} z_{k}, \forall k
\end{gathered}
$$

If $z_{k}=0, v_{k}=0$ is forced by (23), and the feasible interval of $x$ is retained in (22). If $z_{k}=1, v_{k}=x$ is forced by (22), and the feasible interval of $x$ is given in (23). In either case, we have the relation $v_{k}=x z_{k}, k=1, \cdots, K$, so the right-hand side of (21) provides a linear expression of $x y$. The approximation accuracy of binary expansion can be controlled by the number of expansion segments. According to (20), the number of binary variables needed in this approach grows moderately $\left[O\left(\log _{2} K\right)\right.$, where $K$ is the number of expansion segments]. For example, if a continuous variable in the interval $[0,1]$ is approximated by 32 discrete points, then we need 5 binary variables to express the expansion.

In our problem, because the energy contracts interpret optimal solutions of market clearing problems, discrete approximation could miss the exact one, which may cause infeasibility of the KKT condition. Therefore, we expand the bidding strategies $\left(\zeta^{\mathbf{b}}, \xi^{\mathbf{b}}, \chi^{\mathbf{b}}\right)$ through binary variables. Applying (21)-(23) to all production terms in (15a), we obtain the linearized objective 
function (Obj-Lin for short)

$$
\begin{aligned}
\text { Obj-Lin } & =\sum_{t}\left[\xi_{l} p_{t}^{g b}+\Delta \xi \sum_{k=1}^{K} 2^{k-1} z_{t k}^{g b}\right]-\sum_{t} \gamma_{t} p_{t}^{g a s} \\
& +\sum_{t}\left[\chi_{l} h_{t}^{b}+\Delta \chi \sum_{k=1}^{K} 2^{k-1} z_{t k}^{h b}\right] \\
& -\sum_{t}\left[\zeta_{l} p_{t}^{d b}+\Delta \zeta \sum_{k=1}^{K} 2^{k-1} z_{t k}^{d b}\right]
\end{aligned}
$$

In summary, the MILP form of the EH bidding MPEC can be expressed as,

$$
\begin{aligned}
\max & \text { Obj-Lin }(24) \\
\text { s.t. } & \text { EH operation constraints (14) } \\
& \text { Cons-BE }
\end{aligned}
$$

KKT-Lin-Heat

\section{KKT-Lin-Power}

where Cons-BE collects all additional constraints in the form of (22)-(23) introduced by binary expansion; KKT-Lin-Heat and KKT-Lin-Power represent linearized KKT conditions of market clearing problems (8) and (13) after performing the linear disjunctive formulation in (18).

Remark: Incorporating Uncertainties.

In a decision-making problem in PDN, uncertainty usually originates from the market prices and renewable output. In this work, energy prices between the EH and two markets depend on the bidding strategies or bilateral agreements, which are decision variables or constants. The natural gas is supplied by a gas retailer. In view of the current organization of the gas market, the gas fuel price remains constant intraday, which is apparent to the $\mathrm{EH}$ and thus deterministic. However, nodal electricity price at the root bus of PDN is determined by the upper level transmission network which may be uncertain. Moreover, the output of renewable-driven distributed generators could be volatile.

In our current model, uncertain factors are not considered, because we have storage units which can mitigate the negative impact of renewable fluctuations. In other words, system security is not a main concern due to the advent of the EH. Nonetheless, if the economic impact of these uncertain factors are under investigation, we can use the scenario based stochastic programming approach, which minimizes the expected payoff of the EH. More precisely, problem (25) is solved for every scenario with probability $p_{s}, s=1,2, \cdots, n$, the corresponding optimal value is $v_{s}$, then the expected cost is $\sum_{s} p_{s} v_{s}$, because the problem is totally decoupled with respect to scenario.

If the real-time market is considered and a two-stage stochastic model is used to tackle uncertainty factors, the situation would be more complicated, because the day-ahead decision cannot change in the real-time stage. It is very difficult to incorporate uncertainty in the bi-level optimization framework using the scenario stochastic approach. One remedy would be restricting the number of bidding strategies of the energy hub so as to reduce the dimension of decision variables in the day-

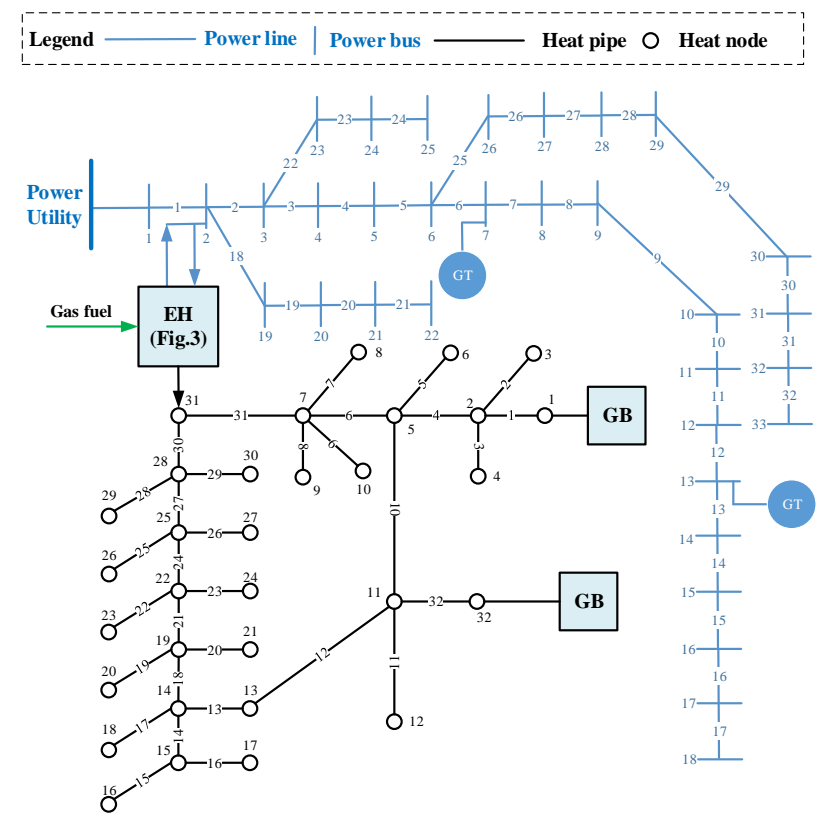

Fig. 5. Topology of the test system.

TABLE I

PARAMETERS OF GENERATORS AND HEAT SOURCES

\begin{tabular}{c|cccc}
\hline GT No. & $p^{g}(\mathrm{MW})$ & $q^{g}(\mathrm{MVar})$ & $\mathrm{a}\left(\$ / \mathrm{MW}^{2}\right)$ & $\mathrm{b}(\$ / \mathrm{MW})$ \\
\hline GT 1 & {$[0,1.5]$} & {$[0,0.5]$} & 0.12 & 20.0 \\
GT 2 & {$[0,2.0]$} & {$[0,1.0]$} & 0.09 & 15.0 \\
\hline Heat No. & $h^{g}(\mathrm{MW})$ & location & $\alpha\left(\$ / \mathrm{MW}^{2}\right)$ & $\beta(\$ / \mathrm{MW})$ \\
\hline GB 1 & {$[0,1.0]$} & Node 1 & 0.15 & 20.0 \\
GB 2 & {$[0,1.0]$} & Node 32 & 0.16 & 18.0 \\
\hline
\end{tabular}

ahead stage. Another is using the proposed deterministic model in the day-ahead market, and adopt a look-ahead bidding (with a few number of periods) in a rolling-horizon fashion for the real-time market, as such uncertainty will be tackled in the real-time stage.

\section{CAse Studies}

\section{A. Basic Configurations}

In this section, numeric experiments are carried out on a test system to validate the effectiveness of the proposed model and method. The system is comprised of a modified IEEE 33-bus $\mathrm{PDN}$ and a 32-node DHN. The EH connects to the PDN at Bus 2 and the DHN at Node 31. System topology is shown in Fig. 5. 2 gas boilers (GB) and 2 gas turbines (GT) produce thermal and electrical energy in the DHN and PDN, respectively. Static var generators with the capacity of 1.0 MVar are placed at Bus 3 and Bus 12 for compensating reactive power and maintaining the voltage profile. Parameters of GTs, GBs, and the EH are listed in Tables I-II. Detailed system data can be found in [53].

In our tests, 128 discrete points $(K=7)$ are used in the binary expansion scheme. For security considerations, the maximum delivered power $\left(p_{0}^{g}\right)$ from the slack bus is $3 \mathrm{MW}$ (also called the feeder capacity) in the PDN, and the maximum gas inflow rates $\left(p^{g a s}\right)$ delivered to the $\mathrm{EH}$ is $1.5 \mathrm{MW}$. The lower bound, upper bound, and average of heat offering prices 
TABLE II

VARIABLE BOUNDS OF THE STUDIED MULTI-CARRIER EH.

\begin{tabular}{cccc}
\hline Variable & Interval & Variable & Interval \\
\hline$p^{c h}$ & {$[0,3.0] \mathrm{MW}$} & $E$ & {$[0,10] \mathrm{MWh}$} \\
$p^{d i s}$ & {$[0,2.0] \mathrm{MW}$} & $H$ & {$[0,10] \mathrm{MWh}$} \\
$h^{c h}$ & {$[0,2.0] \mathrm{MW}$} & $p_{m}^{g b}$ & {$[0,2.0] \mathrm{MW}$} \\
$h^{\text {dis }}$ & {$[0,1.5] \mathrm{MW}$} & $p_{m}^{d b}$ & {$[0,1.5] \mathrm{MW}$} \\
$p^{g a s}$ & {$[0,1.5] \mathrm{MW}$} & $h_{m}^{b}$ & {$[0,1.5] \mathrm{MW}$} \\
$p_{0}^{g}$ & {$[0,3.0] \mathrm{MW}$} & & \\
\hline
\end{tabular}
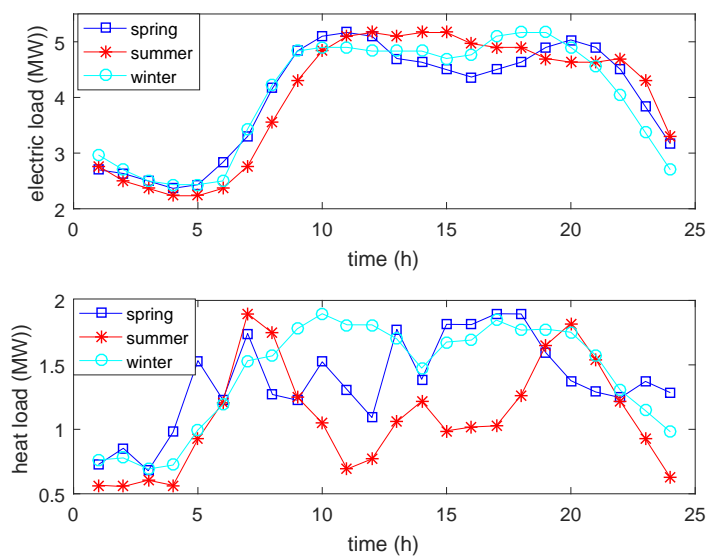

Fig. 6. Heat and electricity load profiles.

$\left(\zeta^{b}\right)$ are $12 \$ / \mathrm{MWh}, 30 \$ / \mathrm{MWh}$, and $25 \$ / \mathrm{MWh}$, respectively. The import electricity price bid $\left(\chi^{b}\right)$ should be no less than the retail price at Bus 2 in period $t$, and the offering price of electricity $\left(\xi^{b}\right)$ should be no greater than the highest daily price multiply 1.25 . The charging and discharging efficiencies of $\operatorname{ESU}\left(\eta_{+}^{e s u} / \eta_{-}{ }^{e s u}\right)$ are equal to $98 \%$, the charging and discharging efficiencies of TSU $\left(\eta_{+}^{t s u} / \eta-^{t s u}\right)$ are set as $98 \%$ too. The efficiency of HP $\left(\eta^{h p}\right)$ is 3 , and the electricity and heating conversion rates $\left(\eta_{e}^{c h p} / \eta_{h}^{c h p}\right)$ of CHP are 0.35 and 0.65 , respectively. All the simulations are programmed with YALMIP [54] by calling CPLEX on a laptop with Intel i54210M CPU and 16GB RAM.

1) Different load profiles: We consider heat and electricity demand curves in different seasons by assuming identical peak load as shown in Fig. 6, in which heat demands exhibit significant difference, while the electricity demand in the summer is the highest during daytime due to the use of air-conditioners.

2) Different market prices: The electricity retail price at Bus 2 (where the energy hub is connected to) is time-varying. This retail price curve is offered by the EMO, and is independent of the dispatch of the energy hub and local generators. We investigate four price curves, the real-time (El-RT) price, the time-of-use (El-TOU) price, the peak-valley (El-PV) price, and an extreme case (El-Ex) price to simulate the different electricity price sequences at Bus 2, as shown in Fig.7.

3) Different gas fuel price: We assume that the gas price is determined by the contract between the $\mathrm{EH}$ and an external gas system, nevertheless, the values can be either constant or time-varying. We investigate three difference scenarios on gas

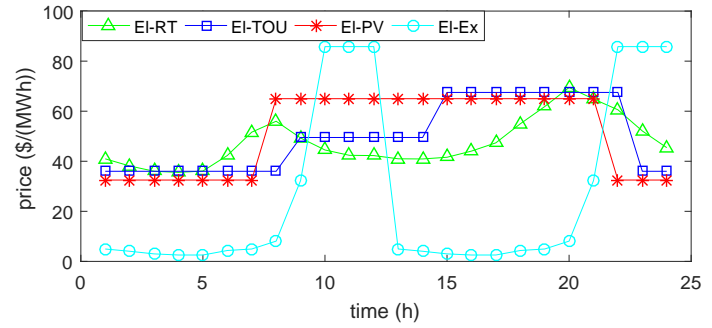

Fig. 7. Retail electricity price profiles at Bus 2.

prices $\gamma$ : In the benchmark (Gas-BEN) case, $\gamma=26 \$ / \mathrm{MWh}$ and remains unchanged; In the gas extreme (Gas-Ex) case, $\gamma=40 \$ / \mathrm{MWh}$ and keeps constant throughout the day; In the peal-valley scenario (Gas-PV), $\gamma=30 \$ / \mathrm{MWh}$ in periods 7-18 and $\gamma=20 \$ /$ MWh in the remaining periods.

4) Storage efficiency: Efficiencies of storage units significantly impact the operation of EH. For the ESU, the round-trip efficiency differs a lot depending on the specific technology. For instance, compressed-air energy storage is around $40 \%$ $60 \%$ [55], pumped storage is approximately $75 \%-85 \%$ [56], and battery storage can reach above $96 \%$. For the TSU, the round-trip efficiency parameter are usually above $98 \%$ [57]. In our tests, we decrease the charging and discharging efficiencies $\left(\eta_{+}^{e s u} / \eta_{-}^{e s u}\right)$ of ESU from $98 \%$ to $60 \%$ (corresponding to decrease the round-trip efficiency from $96 \%$ to $36 \%$ ), and keep the TSU efficiency $\left(\eta_{+}^{t s u} / \eta_{-}^{t s u}\right)$ as a constant of $98 \%$.

5) Market power: The EH possesses market power and its bidding strategies could influence the clearance of the electricity and heat markets. In normal condition, if the offering price is low, the markets would buy more energies from the hub; otherwise, the hub would gradually loss market share because the system operator could dispatch more local generators or heat sources. Sometimes, due to congestion or other security considerations, the system operator has no choice but to buy energy from the EH. To limit its market power, we consider case MP-RtCap, in which the capacity of the feeder in PDN is changed from $3 \mathrm{MW}$ to $6 \mathrm{MW}$; case MP-TBPos, in which GT1 and GT2 are moved to Bus 6 and Bus 13, respectively, and their capacities are increased from $1 \mathrm{MW}$ to $2 \mathrm{MW}$; case MP-GasLim, in which the maximal gas input of EH decreases from $1.5 \mathrm{MW}$ to $1 \mathrm{MW}$.

TABLE III

CORRESPONDENCE BETWEEN SCENARIO AND LOAD/PRICE CURVES

\begin{tabular}{c|c|c|c|c}
\hline \multirow{2}{*}{ scenario } & \multicolumn{2}{|c|}{ load profile } & \multicolumn{2}{c}{ price curve } \\
\cline { 2 - 5 } & electricity & Heat & electricity & natural gas \\
\hline BEN & Winter & Winter & El-RT & Gas-BEN \\
El-TOU & Winter & Winter & El-TOU & Gas-BEN \\
El-PV & Winter & Winter & El-PV & Gas-BEN \\
El-Ex & Winter & Winter & El-Ex & Gas-BEN \\
Spring & Spring & Spring & El-RT & Gas-BEN \\
Summer & Summer & Summer & El-RT & Gas-BEN \\
Gas-Ex & Winter & Winter & El-RT & Gas-Ex \\
Gas-PV & Winter & Winter & El-RT & Gas-PV \\
\hline
\end{tabular}

The load and price curves used in each scenario are sum- 
TABLE IV

PROFIT AND COMPUTATIONAL TIME FOR EACH CASE

\begin{tabular}{c|cc|cc|c|c}
\hline \multirow{2}{*}{ Scenario } & \multicolumn{2}{|c|}{ Cost (\$) } & \multicolumn{2}{|c|}{ Revenue (\$) } & \multirow{2}{*}{ Profit (\$) } & \multirow{2}{*}{ Time (s) } \\
\cline { 2 - 5 } & PDN & Gas & PDN & DHN & & \\
\hline BEN & 278.28 & 598.57 & 951.66 & 394.68 & 469.48 & 231.2 \\
EI-TOU & 331.07 & 489.72 & 993.02 & 397.77 & 569.99 & 62.03 \\
El-PV & 303.23 & 774.96 & 1365.0 & 396.08 & 682.88 & 88.97 \\
El-Ex & 152.30 & 519.09 & 1178.4 & 396.36 & 903.39 & 85.61 \\
Spring & 324.41 & 680.61 & 1106.4 & 378.50 & 479.91 & 197.5 \\
Summer & 301.03 & 538.06 & 947.67 & 309.94 & 418.53 & 28.83 \\
Gas-Ex & 381.41 & 134.54 & 426.12 & 393.79 & 303.95 & 42.77 \\
Gas-PV & 309.14 & 360.00 & 831.99 & 393.79 & 556.64 & 103.9 \\
\hline
\end{tabular}
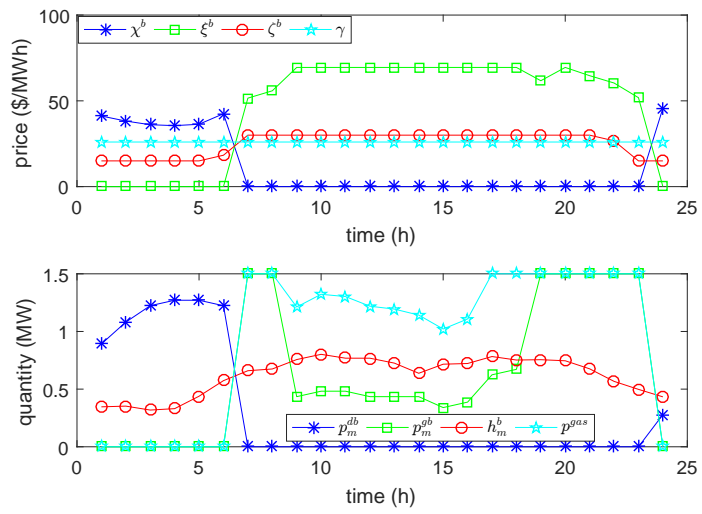

Fig. 8. Price and quantity bid/offer in case BEN.

marized in Table III. Other cases are specified following their first appearance.

\section{B. Results}

The average run time of each test case over 50 randomly generated parameter sets is about several minutes, which is quite inspiring and acceptable for day-ahead market applications. Results in each scenario are summarized in Table IV.

1) The benchmark case: the offering/bidding price and quantity curves are plotted in Fig. 8. Scheduling of storage units and their SoC dynamics are drawn in Fig. 9. The EH purchases electricity with a lower price from the PDN in periods 1-6. A fraction of the purchased electricity is stored in the ESU for potential arbitrage during peak hours, e.g., periods $7-8,19-23$. The peak demand of the DHN is about $2 \mathrm{MW}$, the GBs cannot meet the demands in peak hours of the day. The EH constantly maintains a certain level of thermal energy output. In periods $1-5$, as the electricity is cheap, no gas fuel is purchased, and the thermal energy is produced by HP equipped in the EH. In periods 3 and 5, more heat is converted from the $\mathrm{HP}$ and used to charge the TSU for future usage.

From period 6, the real-time price begins to rise, and the EH switches to consuming gas and producing heat and electricity using the CHP unit. Since the HP has a higher efficiency than the CHP unit, the heat offering price $\zeta^{b}$ in periods 1-5 are smaller than the remaining time of the day during which the heat is produced by the CHP unit. Electricity quantity bids and offers $\left(p_{m}^{g b}, p_{m}^{d b}\right)$, and heat quantity offers $\left(h_{m}^{b}\right)$ are equal to the
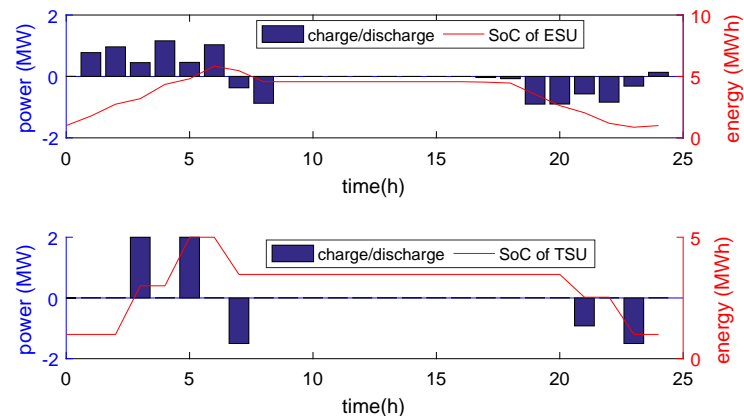

Fig. 9. SoCs of the ESU and TSU inside the EH.
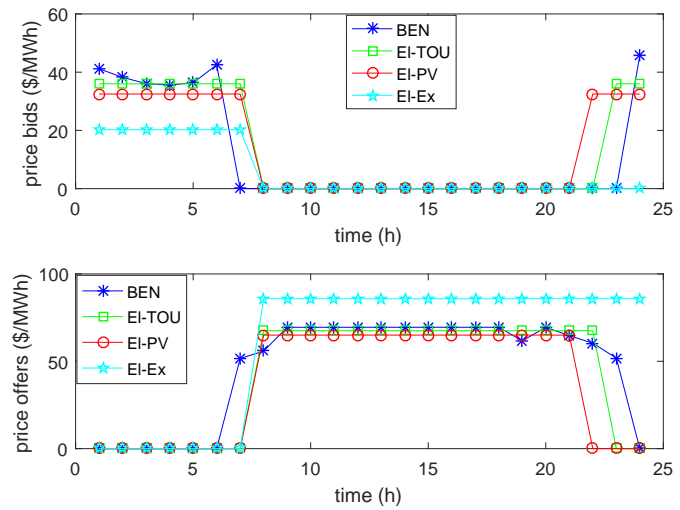

Fig. 10. Electricity price bids and offers versus electricity price curves.

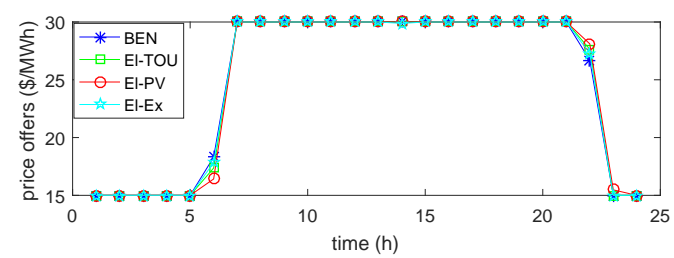

Fig. 11. Heat price offers versus electricity price curves.

cleared values. Through the cross-arbitrage among electricity market, gas market, and heat market, the EH gains a profit of $\$ 469.48$.

2) Impact of electricity and gas prices: prices of electricity and gas have pivotal influences on the actions of EH. Electricity price bids $\left(\chi^{b}\right)$ and offers $\left(\xi^{b}\right)$, and heat price bids $\left(\zeta^{b}\right)$ in ElTOU, El-PV, and El-Ex scenarios are shown in Fig.10 and Fig.11, respectively. With the given price curve in scenario ElEx, the EH bids the lowest electricity offering price $\left(\xi^{b}\right)$ during periods 1-6 and highest heat offering price $\left(\chi^{b}\right)$ during periods $8-24$, and gains the highest arbitrage revenue of $\$ 1178.4$ and the highest profit of $\$ 903.39$. The electricity price mechanisms have little impacts on heat price offers as indicated in Fig.11. This is because during periods 7-21, the heat demand is high, so the EH possesses strong market power, and the heat offering price quickly reaches the upper bound.

The amounts of purchased gas fuel in the BEN scenario, the Gas-PV scenario, and the Gas-Ex scenario are compared 


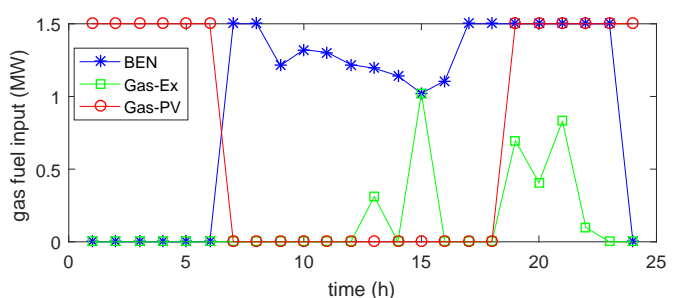

Fig. 12. Purchased gas fuel versus gas price curves.
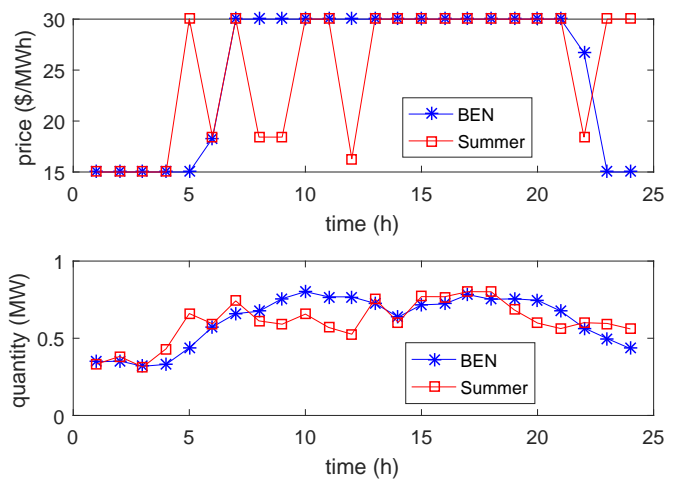

Fig. 13. Heat price and quantity offers for BEN and Summer.

in Fig.12. Once the gas price is increased from $26 \$ / \mathrm{MWh}$ to $40 \$ / \mathrm{MWh}$ in case Gas-EX, we can see that the EH alters its strategy to purchasing electricity from the PDN instead of purchasing gas in peak-hours as in case BEN. This strategy uses HP to produce adequate thermal energy which is reserved in TSU so as to meet heat demands without using expensive natural gas. Consequently, the PDN revenue and the profit of EH in the Gas-Ex scenario are the lowest in Table IV. With the deepened integration of energy systems, real-time gas market may appear in the future, from which the EH can benefit by making full use of the cheap gas during off-peak hours. It is also observed in Fig.12 that the EH purchases more natural gas in Gas-PV case than it does in Gas-Ex case as the gas price is lower, and receives more revenue from the electricity market since the production cost of the CHP unit declines. Compared with the BEN case, the gas purchasing cost is lower in Gas-PV case because gas is bought during off-peak hours. As a result, the total revenue in Gas-PV case is the highest. Certainly, this conclusion is not universal and depends on actual price data.

3) Impact of load shape: The offering prices and quantities of heat in the BEN case (the Winter scenario) and the Summer scenario are compared in Fig. 13. Since the total heat demand in Summer is lower than that in Winter, the revenue of selling heat to DHN, as well as the total profit, is smaller than that in the BEN case.

4) Impact of storage efficiency: In this set of tests, TOU electricity price curve in Fig. 7 is used; the efficiency of TSU is equal to $98 \%$. The efficiency parameter of ESU varies, and results are listed in Table V. It is observed that when $\eta_{+}^{\text {esu }}>75 \%$, the efficiency significantly impacts the total revenue; further decrease in $\eta_{+}^{e s u} / \eta_{-}^{e s u}$ does not have much influence on the total profit, because the EH scarcely arbitrages
TABLE V

PROFIT OF ENERGY HUB UNDER DIFFERENT ESU EFFICIENCY PARAMETERS $(\$)$

\begin{tabular}{c|cc|cc|c}
\hline \multirow{2}{*}{$\eta_{+}^{e s u} / \eta_{-}^{e s u}$} & \multicolumn{2}{|c|}{ Cost } & \multicolumn{2}{|c|}{ Revenue } & \multirow{2}{*}{ Profit } \\
\cline { 2 - 5 } & PDN & Gas & PDN & DHN & \\
\hline $98 \%$ & 331.07 & 489.72 & 993.02 & 397.77 & 569.99 \\
$95 \%$ & 330.55 & 528.97 & 993.02 & 397.77 & 531.27 \\
$90 \%$ & 310.78 & 594.93 & 993.02 & 395.98 & 483.29 \\
$85 \%$ & 313.13 & 605.99 & 946.48 & 394.68 & 425.72 \\
$80 \%$ & 315.78 & 493.53 & 787.64 & 397.66 & 375.98 \\
$75 \%$ & 318.78 & 493.53 & 749.08 & 398.38 & 335.15 \\
$70 \%$ & 63.41 & $\mathbf{4 9 3 . 5 3}$ & $\mathbf{4 7 4 . 9 4}$ & $\mathbf{3 9 8 . 3 9}$ & 316.39 \\
$65 \%$ & 67.18 & $\mathbf{4 9 3 . 5 3}$ & $\mathbf{4 7 4 . 9 4}$ & $\mathbf{3 9 8 . 3 9}$ & 312.62 \\
$60 \%$ & 72.98 & $\mathbf{4 9 3 . 5 3}$ & $\mathbf{4 7 4 . 9 4}$ & $\mathbf{3 9 8 . 3 9}$ & 306.82 \\
\hline
\end{tabular}

TABLE VI

TEST ON MARKET POWER OF THE ENERGY HUB(\$)

\begin{tabular}{c|cc|cc|c}
\hline \multirow{2}{*}{ Scenario } & \multicolumn{2}{|c|}{ Cost } & \multicolumn{2}{|c|}{ Revenue } & \multirow{2}{*}{ Profit } \\
\cline { 2 - 5 } & PDN & Gas & PDN & DHN & \\
\hline MP-GasLim & 314.96 & 564.95 & 951.66 & 394.68 & 466.44 \\
MP-TBPos & 401.61 & 416.41 & 872.68 & 396.37 & 451.02 \\
MP-RtCap & 863.39 & 9.77 & 916.74 & 393.79 & 439.94 \\
\hline
\end{tabular}

electricity, and the revenue from the PDN mainly comes from selling electricity generated by the CHP unit which burns gas. Purchased electricity from the PDN is stored in ESU or converted to heat for supplying demands. From the last three rows of Table $\mathrm{V}$, it is observed that more electricity charging cost is necessitated to support the total arbitrage since the electricity charging efficiency is lower. Nevertheless, the minimum profit can be guaranteed by consuming natural gas, demonstrating the advantage of multi-carrier energy integration.

5) Market power mitigation: Results in the three cases defined in subsection A are illustrated in Figs. 14-16. Through limiting the maximal gas delivery rate in case MP-GasLim, the EH consumes less gas during day-time than it does in case BEN and imports more electricity in period 24 as shown in Fig. 15. Since the electricity offering price is high, which can be seen from Fig. 16, the change in the total revenue is tiny $(\$ 469.48$ v.s. \$466.44). The revenue in the heating market remains the same.

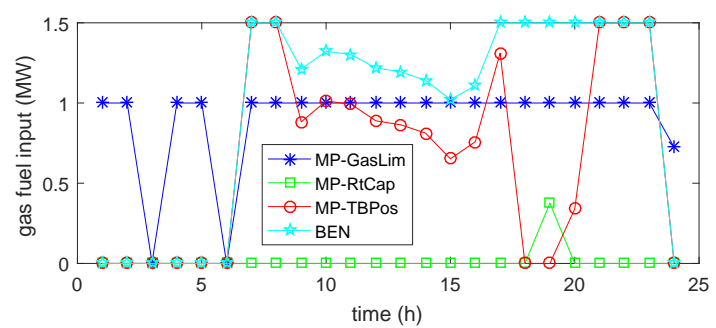

Fig. 14. Gas fuel input for market power test.

In case MP-TBPos, GT1 has more capacity to support peak electricity load, the electricity quantity offer $\left(p_{t, m}^{g b}\right)$ during periods 9-17 is lower than that in case BEN, as shown in Fig.15. Since the sold electricity decreases compared to case 

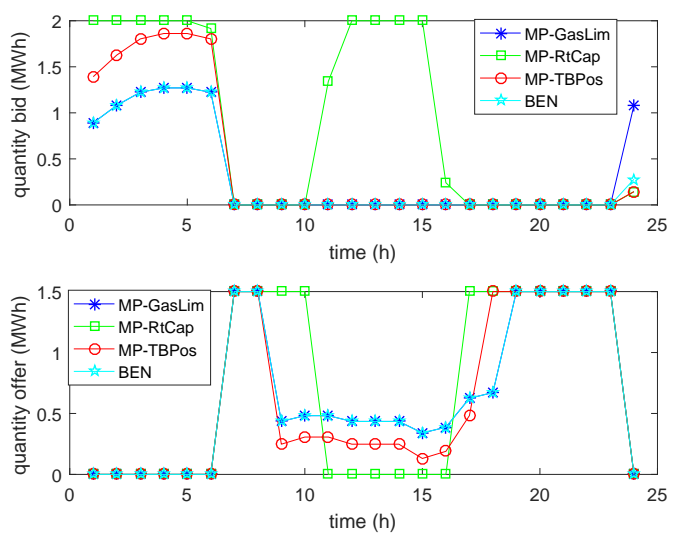

Fig. 15. Electricity quantity bid and offer for market power test.

MP-GasLim, the gas fuel import reduces during peak hours, which can be seen in Fig.14. Meanwhile, more electricity is purchased during off-peak hours (1-6), as indicated in Fig.15, to compensate the decrease of gas contract. Furthermore, since GTs offer more electricity in case MP-TBPos, the offering price $\left(\xi^{b}\right)$ in period 18 is lower than case BEN.
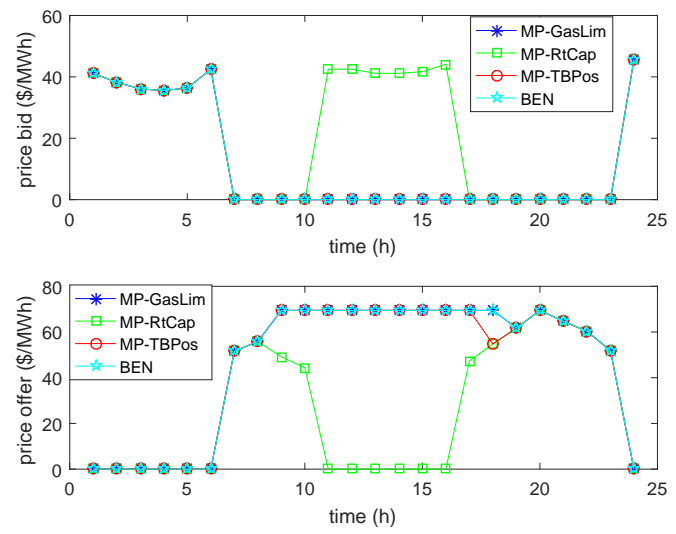

Fig. 16. Electricity price bid and offer for market power test.

Another way to limit the market power of $\mathrm{EH}$ is to increase the capacity of the feeder (distribution line connecting to the slack bus). In case MP-RtCap, because more cheaper electricity can be delivered to consumers, the EH losses certain market share and purchases very little gas as indicated in Fig.14. Since more electricity is supplied to the PDN from the upper grid, to maintain total revenue, the EH sells the electricity with a lower price than other cases in periods $9,10,16$, and 17 , as indicated in Fig. 16. Since less gas is purchased in case MP-RtCap (as in Fig.14) and heat can only be generated through HP by consuming electricity, more electricity is purchased during periods 1-7 and 11-16 to supply heat demand. Electricity arbitrage is the main source of profit in this case, which can be observed from the price and quantity curves in Figs. 15-16.

\section{CONCLUSiOnS}

The paper proposes systematic modelling and computational methods for profit-driven energy hubs participating in distri- bution electricity and heating markets. The strategic bidding problem of the energy hub accounting for the market clearing problems is formulated through an MPEC. In order to solve this problem in a systematic way, we develop an MILP approximation model based on optimality condition transformation and integer programming techniques. Case studies show that the profit of energy hub is mainly affected by the natural gas prices and storage efficiencies in a certain range, and a minimal profit can be maintain under extreme price scenario of either gas fuel or electricity retail price by switching to the alternative energy resource.

The proposed model and method can provide useful information in various applications. An energy hub owner can use the proposed method to determine the optimal bidding strategies in the electricity and heating market; An investor can use the model to examine the profit of energy hub under a given system design, which helps him to select better plans; The government agency can use the model to investigate the market power of the energy hub and the equilibrium state in the integrated energy system, so as to decide on critical market parameter (such as the maximum offering price) and maintain market fairness.

\section{REFERENCES}

[1] H. Lund, S. Werner, R. Wiltshire, S. Svendsen, J. E. Thorsen, F. Hvelplund, and B. V. Mathiesen, "4th generation district heating (4GDH): Integrating smart thermal grids into future sustainable energy systems," Energy, vol. 68, pp. 1-11, Apr 2014.

[2] M. Geidl and G. Andersson, "Optimal power flow of multiple energy carriers," IEEE Trans. Power Syst, vol. 22, no. 1, pp. 145-155, Feb 2007.

[3] A. Shabanpour-Haghighi and A. R. Seifi, "Energy flow optimization in multicarrier systems," IEEE Trans. Ind. Informat, vol. 11, no. 5, pp. 1067-1077, Oct 2015.

[4] Z. Li, W. Wu, M. Shahidehpour, J. Wang, and B. Zhang, "Combined heat and power dispatch considering pipeline energy storage of district heating network," IEEE Trans. Sustain. Energy, vol. 7, no. 1, pp. 12-22, Jan 2016.

[5] M. Geidl, G. Koeppel, P. Favre-Perrod, B. Klockl, G. Andersson, and $\mathrm{K}$. Frohlich, "Energy hubs for the future," IEEE Power and Energy Magazine, vol. 5, no. 1, pp. 24-30, Jan 2007.

[6] Y. Wang, N. Zhang, C. Kang, D. Kirschen, J. Yang, and Q. Xia, "Standardized matrix modeling of multiple energy systems," IEEE Trans. Smart Grid, in press.

[7] R. Evins, K. Orehounig, V. Dorer, and J. Carmeliet, "New formulations of the energy hub model to address operational constraints," Energy, vol. 73, pp. 387-398, Aug 2014.

[8] A. Shabanpour-Haghighi and A. Seifi, "Energy flow optimization in multicarrier systems," IEEE Trans. Industrial Informatics, vol. 11, no. 5, pp. 1067-1077, Oct 2015.

[9] M. Moeini-Aghtaie, A. Abbaspour, and M. Fotuhi-Firuzabad, "A decomposed solution to multiple-energy carriers optimal power flow," IEEE Trans. Power Syst., vol. 29, no. 2, pp. 707-716, Mar 2014.

[10] M. Bozchalui, S. Hashmi, H. Hassen, C. Cañizares, and K. Bhattacharya, "Optimal operation of residential energy hubs in smart grids," IEEE Trans. Smart Grid, vol. 3, no. 4, pp. 1755-1766, Dec 2012.

[11] S. Paudyal, C. Cañizares, and K. Bhattacharya, "Optimal operation of industrial energy hubs in smart grids," IEEE Trans. Smart Grid, vol. 6, no. 2, pp. 684-694, Mar 2015.

[12] A. Parisio, C. D. Vecchio, and A. Vaccaro, "A robust optimization approach to energy hub management," Int. J. Electrical Power \& Energy Systems, vol. 42, no. 1, pp. 98-104, Nov 2012.

[13] M. Rastegar, M. Fotuhi-Firuzabad, H. Zareipour, and M. MoeiniAghtaieh, "A probabilistic energy management scheme for renewablebased residential energy hubs," IEEE Trans. Smart Grid, vol. 8, no. 5, pp. 2217-2227, Sep 2017.

[14] S. Manshadi and M. Khodayar, "Resilient operation of multiple energy carrier microgrids," IEEE Trans. Smart Grid, vol. 6, no. 5, pp. 22832292, Sep 2015. 
[15] X. Zhang, M. Shahidehpour, A. Alabdulwahab, and A. Abusorrah, "Optimal expansion planning of energy hub with multiple energy infrastructures," IEEE Trans. Smart Grid, vol. 6, no. 5, pp. 2303-2311, Sep 2015.

[16] X. Zhang, L. Che, M. Shahidehpour, A. Alabdulwahab, and A. Abusorrah, "Reliability-based optimal planning of electricity and natural gas interconnections for multiple energy hubs," IEEE Trans. Smart Grid, vol. 8, no. 4, pp. 1658-1667, Jul 2017.

[17] A. Shahmohammadi, M. Moradi-Dalvand, H. Ghasemi, and M. Ghazizadeh, "Optimal design of multicarrier energy systems considering reliability constraints," IEEE Trans. Power Del., vol. 30, no. 2, pp. 878886, Apr 2015.

[18] S. Pazouki and M. Haghifam, "Optimal planning and scheduling of energy hub in presence of wind, storage and demand response under uncertainty," Int. J. Electrical Power \& Energy Systems, vol. 80, pp. 219-239, Sep 2016.

[19] W. Huang, N. Zhang, J. Yang, Y. Wang, and C. Kang, "Optimal configuration planning of multi-energy systems considering distributed renewable energy," IEEE Trans. Smart Grid, in press, 2017.

[20] K. Orehounig, R. Evins, and V. Dorer, "Integration of decentralized energy systems in neighbourhoods using the energy hub approach," Appl. Energy, vol. 154, pp. 277-289, Sep 2015.

[21] P. M. Sotkiewicz and J. M. Vignolo, "Nodal pricing for distribution networks: efficient pricing for efficiency enhancing dg," IEEE Trans. Power Syst., vol. 21, no. 2, pp. 1013-1014, May 2006.

[22] G. T. Heydt, B. H. Chowdhury, M. L. Crow, D. Haughton, B. D. Kiefer, F. Meng, and B. R. Sathyanarayana, "Pricing and control in the next generation power distribution system," IEEE Trans. Smart Grid, vol. 3, no. 2, pp. 907-914, Jan 2012.

[23] N. Li, "A market mechanism for electric distribution networks," in Decision and Control (CDC), 2015 IEEE 54th Annual Conference on. IEEE, Dec 2015, pp. 2276-2282.

[24] J. Song, F. Wallin, and H. Li, "District heating cost fluctuation caused by price model shift," Applied energy, vol. 194, pp. 715-724, May 2017.

[25] A. Korppoo and N. Korobova, "Modernizing residential heating in russia: End-use practices, legal developments, and future prospects," Energy Policy, vol. 42, pp. 213-220, Mar 2012.

[26] M. Andersson, "Shadow prices for heat generation in time-dependent and dynamic energy systems," Energy, vol. 19, no. 12, pp. 1205-1211, Dec 1994.

[27] A. Poredoš and A. Kitanovski, "Exergy loss as a basis for the price of thermal energy," Energy Conversion and Management, vol. 43, no. 16, pp. 2163-2173, Nov 2002.

[28] A. M. Quelhas, E. Gil, and J. D. McCalley, "Nodal prices in an integrated energy system," International Journal of Critical Infrastructures, vol. 2, no. 1, pp. 50-69, Dec 2005.

[29] J. Zhang, B. Ge, and H. Xu, "An equivalent marginal cost-pricing model for the district heating market," Energy Policy, vol. 63, pp. 1224-1232, Dec 2013.

[30] H. Li, Q. Sun, Q. Zhang, and F. Wallin, "A review of the pricing mechanisms for district heating systems," Renewable and Sustainable Energy Reviews, vol. 42, pp. 56-65, Feb 2015.

[31] A. Arabkoohsar and G. B. Andresen, "Dynamic energy, exergy and market modeling of a high temperature heat and power storage system," Energy, vol. 126, pp. 430-443, May 2017.

[32] M. Yazdani-Damavandi, N. Neyestani, M. Shafie-khah, J. Contreras, and J. Catalao, "Strategic behavior of multi-energy players in electricity markets as aggregators of demand side resources using a bi-level approach," IEEE Trans. Power Syst. in press, 2017.

[33] A. Najafi, H. Falaghi, J. Contreras, and M. Ramezani, "A stochastic bilevel model for the energy hub manager problem," IEEE Trans. Smart Grid, vol. 8, no. 5, pp. 2394-2404, Sep 2017.

[34] A. Sheikhi, M. Rayati, S. Bahrami, and A. Ranjbar, "Integrated demand side management game in smart energy hubs," IEEE Trans. Smart Grid, vol. 6, no. 2, pp. 675-683, Mar 2015.

[35] S. Bahrami, M. Toulabi, S. Ranjbar, M. Moeini-Aghtaie, and A. M. Ranjbar, "A decentralized energy management framework for energy hubs in dynamic pricing markets," IEEE Trans. Smart Grid, in press, 2017.

[36] V. Davatgaran, M. Saniei, and S. S. Mortazavi, "Optimal bidding strategy for an energy hub in energy market," Energy, vol. 148, pp. 482-493, Apr 2018.

[37] H.-G. Yeh, D. F. Gayme, and S. H. Low, "Adaptive var control for 1068 distribution circuits with photovoltaic generators," IEEE Trans. Power Syst., vol. 27, no. 3, pp. 1656-1663, Aug 2012.
[38] X. Liu, J. Wu, N. Jenkins, and A. Bagdanavicius, "Combined analysis of electricity and heat networks," Appl. Energy, vol. 162, pp. 1238-1250, Jan 2016.

[39] I. del Hoyo Arce, S. H. López, S. L. Perez, M. Rämä, K. Klobut, and J. A. Febres, "Models for fast modelling of district heating and cooling networks," Renewable and Sustainable Energy Reviews, vol. 82, no. 2, pp. 1863-1873, Jul 2017.

[40] M. Pirouti, A. Bagdanavicius, J. Ekanayake, J. Wu, and N. Jenkins, "Energy consumption and economic analyses of a district heating network," Energy, vol. 57, pp. 149-159, Aug 2013.

[41] Z. Wang, B. Chen, J. Wang, M. M. Begovic, and C. Chen, "Coordinated energy management of networked microgrids in distribution systems," IEEE Trans. Smart Grid, vol. 6, no. 1, pp. 45-63, Jan 2015.

[42] H.-G. Yeh, D. F. Gayme, and S. H. Low, "Adaptive var control for distribution circuits with photovoltaic generators," IEEE Trans. Power Syst., vol. 27, no. 3, pp. 1656-1663, Aug 2012.

[43] Z. Wang, H. Chen, J. Wang, and M. Begovic, "Inverter-less hybrid voltage/var control for distribution circuits with photovoltaic generators," IEEE Trans. Smart Grid, vol. 5, no. 6, pp. 2718-2728, Nov 2014.

[44] L. Bai, J. Wang, C. Wang, C. Chen, and F. F. Li, "Distribution locational marginal pricing (DLMP) for congestion management and voltage support," IEEE Transactions on Power Systems, Oct 2017.

[45] A. Bagdanavicius and N. Jenkins, "Exergy and exergoeconomic analysis of a compressed air energy storage combined with a district energy system," Energy Conversion and Management, vol. 77, pp. 432-440, Jan 2014.

[46] S. Mei, R. Li, X. Xue, Y. Chen, Q. Lu, X. Chen, C. D. Ahrens, R. Li, and L. Chen, "Paving the way to smart micro energy grid: concepts, design principles, and engineering practices," CSEE Journal of Power and Energy Systems, vol. 3, no. 4, pp. 440-449, Dec 2017.

[47] D. Cocco, M. Petrollese, and V. Tola, "Exergy analysis of concentrating solar systems for heat and power production," Energy, vol. 130, pp. 192203, Jul 2017.

[48] R. Li, L. Chen, B. Zhao, W. Wei, F. Liu, X. Xue, S. Mei, and T. Yuan, "Economic dispatch of an integrated heat-power energy distribution system with a concentrating solar power energy hub," Journal of Energy Engineering, vol. 143, no. 5, p. 04017046, Jun 2017.

[49] Z.-Q. Luo, J.-S. Pang, and D. Ralph, Mathematical programs with equilibrium constraints. Cambridge University Press, Nov 1996.

[50] J. Fortuny-Amat and B. McCarl, "A representation and economic interpretation of a two-level programming problem," Journal of the Operational Research Society, pp. 783-792, Sep 1981.

[51] M. V. Pereira, S. Granville, M. H. Fampa, R. Dix, and L. A. Barroso, "Strategic bidding under uncertainty: a binary expansion approach," IEEE Trans. Power Syst., vol. 20, no. 1, pp. 180-188, Feb 2005.

[52] C. Ruiz, A. J. Conejo, and S. A. Gabriel, "Pricing non-convexities in an electricity pool," IEEE Trans. Power Syst., vol. 27, no. 3, pp. 1334-1342, Aug 2012

[53] R. Li, "Integrated heat-power system dataset," 2018, [online] Available at: https://sites.google.com/site/ruilismarterrlc.

[54] J. Löfberg, "YALMIP : A toolbox for modeling and optimization in MATLAB," in In Proceedings of the CACSD Conference, Taipei, Taiwan, 2004.

[55] E. Drury, P. Denholm, and R. Sioshansi, "The value of compressed air energy storage in energy and reserve markets," Energy, vol. 36, no. 8, pp. 4959-4973, Aug 2011.

[56] Y. Kong, Z. Kong, Z. Liu, C. Wei, J. Zhang, and G. An, "Pumped storage power stations in china: The past, the present, and the future," Renewable and Sustainable Energy Reviews, vol. 71, pp. 720-731, May 2017.

[57] S. Kuravi, J. Trahan, D. Y. Goswami, M. M. Rahman, and E. K. Stefanakos, "Thermal energy storage technologies and systems for concentrating solar power plants," Progress in Energy and Combustion Science, vol. 39, no. 4, pp. 285-319, Aug 2013. 


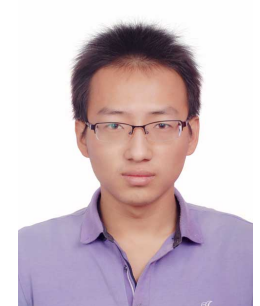

Rui Li (S'17) received the B.S. degree from North China Electric Power University, Baoding, China, in 2014. He is pursuing the Ph.D. degree at Tsinghua University, Beijing, China.

$\mathrm{He}$ was a visiting Ph.D. student at Argonne National Laboratory from Nov. 2016 to Mar. 2017. Currently, he is a visiting Ph.D. student at Harvard University. His research interests include reinforcement learning, compressed air energy storage, thermodynamic analysis, high-performance computation, and carbon fiber recycling.

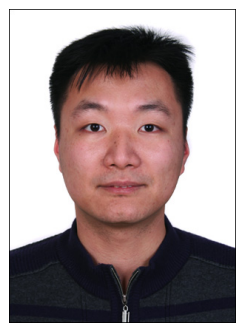

Wei Wei (M'15) received the B.Sc. and Ph.D. degrees in electrical engineering from Tsinghua University, Beijing, China, in 2008 and 2013, respectively.

He was a Postdoctoral Researcher with Tsinghua University from 2013 to 2015. He was a Visiting Scholar with Cornell University, Ithaca, NY, USA, in 2014, and with Harvard University, Cambridge, MA, USA, in 2015. He is currently an Assistant Professor with Tsinghua University. His research interests include applied optimization and energy economics.

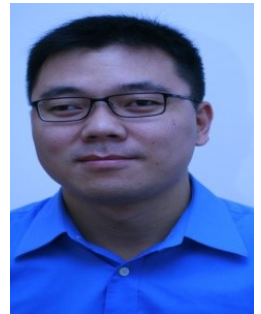

Qiuwei Wu (M'08-SM'15) obtained the B. Eng. and M. Eng. in Power System and Its Automation from Nanjing University of Science and Technology, Nanjing, China, in 2000 and 2003, respectively. He obtained the PhD degree in Power System Engineering from Nanyang Technological University, Singapore, in 2009 .

He was a senior R\&D engineer with VESTAS Technology R\&D Singapore Pte Ltd from Mar. 2008 to Oct. 2009. He has been working at Department of Electrical Engineering, Technical University of Denmark (DTU) since Nov. 2009 (PostDoc Nov. 2009-Oct. 2010, Assistant Professor Nov. 2010-Aug. 2013, Associate Professor since Sept. 2013). He was a visiting scholar at Department of Industrial Engineering \& Operations Research (IEOR), University of California, Berkeley, from Feb. 2012 to May 2012 funded by Danish Agency for Science, Technology and Innovation (DASTI), Denmark. He was a visiting professor named by Y. Xue, an Academician of Chinese Academy of Engineering, at Shandong University, China, from Nov. 2015 to Oct. 2017. Currently, he is a visiting scholar at School of Engineering and Applied Science, Harvard University.

His research area is power system operation and control with high renewables, including wind power modelling and control, active distribution networks, and integrated energy systems. He is an Editor of IEEE Transactions on Smart Grid and IEEE Power Engineering Letters. He is also an Associate Editor of International Journal of Electrical Power and Energy Systems, Journal of Modern Power Systems and Clean Energy, IET Renewable Power Generation, and IET Generation, Transmission \& Distribution.

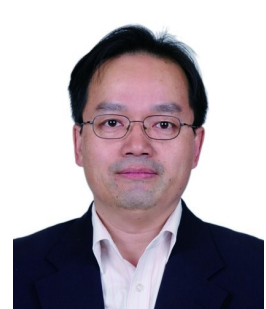

Shengwei Mei (SM'06-F'14) received the B.Sc. degree in mathematics from Xinjiang University, Urumqi, China, the M.Sc. degree in operations research from Tsinghua University, Beijing, China, and the Ph.D. degree in automatic control from Chinese Academy of Sciences, Beijing, China, in 1984, 1989 and 1966, respectively.

$\mathrm{He}$ is currently a Professor at Tsinghua University. His research interests include power system analysis and control, compressed air energy storage, game theory, and its application in power systems.

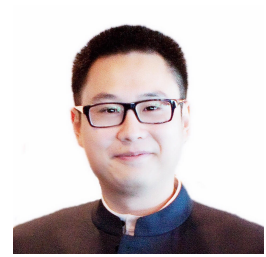

Qinran Hu (S'11-M'15) received the B.S. degree from Chien-Shiung Wu Honors College, Southeast University (China) in 2010, and the M.S. and Ph.D. degrees from the University of Tennessee, Knoxville, TN, USA in 2013 and 2015, respectively.

$\mathrm{He}$ is currently a postdoc fellow in Harvard University, Cambridge, MA, USA. His research interests include power system optimization, demand aggregation, and electricity market. 